\title{
High-Efficiency Step-down Converter for On-board Thermoelectric Generators on Heavy Duty Vehicles
}

\author{
Arash Edvin Risseh ${ }^{1}$ \\ H-P. Nee ${ }^{1}$ \\ ${ }^{1}$ School of Electrical Engineering, \\ KTH Royal Institute of Technology \\ Teknikringen 33, Stockholm, Sweden
}

\begin{abstract}
Today's combustion engines have low efficiency and a large amount of useful energy converts to heat as waste in different type of vehicles. Improving the dynamics of the car body, injection system, the shape of the internal engine components and manipulating the fuel compositions have had influence on fuel economy, but still less than $50 \%$ of energy in the fuel is converted to useful mechanical power. Since the lost energy escapes through the exhaust system as heat, taking advantage of thermoelectricity, part of that energy can be converted to useful electrical energy, improving the overall efficiency. However, the output voltage from a thermoelectric generator is a function of hot and cold side temperature and since, the electrical system of the vehicle operates with constant voltage, the use of a power converter is necessary. In this paper, simulation and experimental results of such a high-efficiency converter (94-96 \%), designed for thermoelectric generators on heavy duty vehicles is presented and discussed.
\end{abstract}

Keywords- DC-DC converter, synchronous converter, power management, thermoelectric generator, waste heat recovery, thermoelectric energy harvesting.

\section{INTRODUCTION}

Due to global warming and the fact that the vehicle population passed 1 billion year 2010, the demand for efficient transportation is higher than ever [1], [2]. According to the typical energy flow of combustion engine, depending on the operating point or engine load, between $30 \%$ to $40 \%$ of the fuel energy in a diesel engine converts to thermal energy and releases through the exhaust system. Part of this energy can easily be recovered using a thermoelectric generator (TEG), which is manufactured by connecting a number of thermoelectric modules (TEM) together. A thermoelectric module is made by a series of p- and n-type semiconductors which operate based on the Seebeck effect when exposed to a temperature gradient, see Fig. 1, [3]. A TEG offers a non-moving, compact and noise-free energy conversion system and due to its simplicity it can be used in various applications such as waste heat recovery applications. Due to the temperature limitations on the hot and cold sides of the TEM, and also in order to extract as much as possible thermal energy, a proper exhaust heat exchanger should be designed [4]. Since the exhaust temperature is a function of the engine load, and the electrical properties of the TEM are also dependent on the hot and cold side temperatures, a power converter between the TEG and the electrical system of the vehicle should hence be employed.

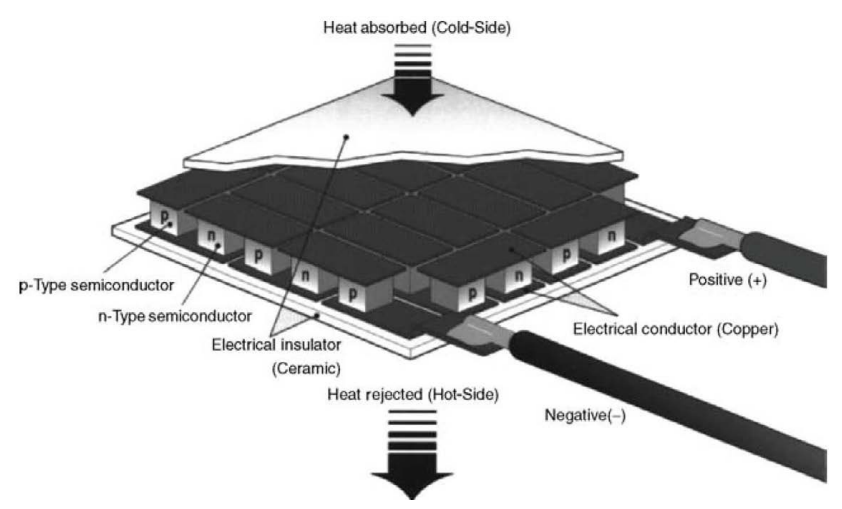

Fig. 1. Typical thermoelectric module.

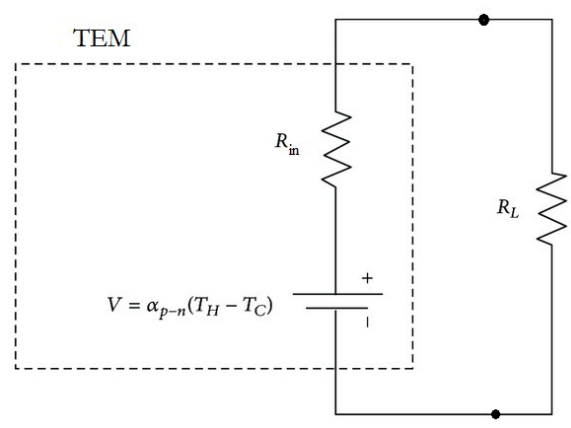

Fig. 2. V-R model of a thermoelectric module.

Different types of converters and control systems have been proposed for TEGs during the last years. In [5]-[8] step-up converters with high efficiency were proposed. However, as explained in [9] there are some related general issues of step-up converters that makes them less attractive for use in the automotive industry where simplicity and economy is high prioritized. As seen in Fig. 2 a TEM can be modeled as an ideal voltage source and a series resistance. According to [10], if the temperature difference over a number of TEMs is constant, the difference of the output power of the string is not significant if the TEMs are connected in series or in parallel. This gives the possibility to connect a string of TEMs in series to create enough voltage to have a step-down converter connected as the power conditioner. Moreover, the step-down converter has a linear transfer function while the step-up and step-up/down are non-linear systems in the continuous 


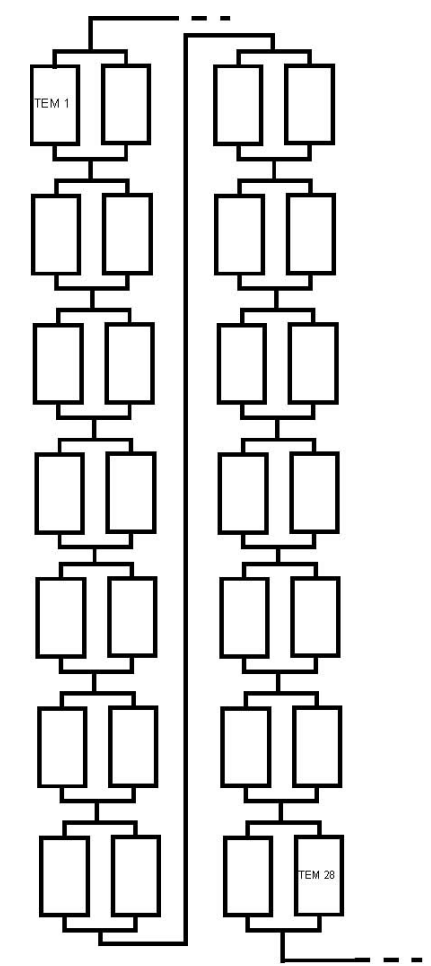

Fig. 3. Schematic of the TEG made by 28 thermoelectric modules connected in parallel two by two and in series with each other.

operating mode which is a clear advantage when developing control system.

A thermoelectric generator containing 28 modules was designed according to Fig. 3 and placed in the exhaust system of a Scania heavy duty vehicle. Based on a typical 9 point driving cycle for the truck, the hot and cold temperature over the modules was calculated and different voltages and powers were obtained. A high-efficiency synchronous step-down converter was designed and simulated. Later on, the design was built and tested with the same voltage and power from the TEG. The results of the simulation and experiment of the converter are presented in this paper.

\section{Converter Design And Simulation Results}

Due to the low conversion efficiency of thermoelectricity, a highly efficient power conditioner in a thermoelectric waste heat recovery system is desired. A synchronous converter usually has a higher efficiency than a non-synchronous converter since an active switch with lower voltage drop and faster switching time is employed. On the other hand, in a non-synchronous converter, diodes with higher voltage drop and longer reverse recovery times are used. Clearly, the last mentioned converter has higher switching- and conducting losses and thereby lower efficiency. Therefore, for this application a synchronous step-down converter is proposed. However, it is important to be able to control the high- and low-side switches and to adjust the dead time depending on the raise- and fall times which have a significant effect on the losses in the system.

The converter components were chosen and designed based on Table I. Two similar silicon devices with $250 \mathrm{~V}$ rated
TABLE I

PROPOSED CONVERTER COMPONENTS AND PARAMETERS.

\begin{tabular}{|c|c|}
\hline Component/Parameter & Value/Model \\
\hline Frequency, Fs & $100 \mathrm{kHz}$ \\
Inductance, L & $650 \mu \mathrm{H}$ \\
Switch & IPB200N25N3 \\
$\mathrm{C}_{\text {in }}$ & $100 \mu \mathrm{F} / 107 \mathrm{TTA} 350 \mathrm{M}$ \\
$\mathrm{C}_{\text {out }}$ & $100 \mu \mathrm{F} / 107 \mathrm{TTA} 350 \mathrm{M}$ \\
Gate Driver & $\mathrm{ADuM} 4224$ \\
\hline
\end{tabular}

drain-source voltage and $R_{D S(\text { on) }}$ of $25 \mathrm{~m} \Omega$ were used as switches. For the experiment, a low loss $650 \mu \mathrm{H}$ inductor was constructed and the internal parameters were measured. Since the internal resistance of the TEG is relatively high, to reduce the voltage ripple at the input and output, the capacitor values should be calculated accurately. The simulations were performed in OrCAD/Pspice with the model shown in Fig. 4. The model used for the switches was provided by the manufacturer. To increase the reliability of the simulation results, parasitic components were added to the standard models of some components. For example, additional elements of the real capacitor were added to the standard model using data sheet values. The resistance and capacitance of the inductor were included in the simulation model as well. Since the simulation model of the gate driver was not available, a simple model of the component was built in accordance with the data sheet and the ability to source and sink current to the gates of the switches. A relatively high gate resistance of $8 \Omega$ was used to reduce the drain-source voltage oscillations.

The input parameters to the simulation were the open circuit voltage, internal resistance and the duty ratio which affects, among others, the amount of delivered power to the load. The highest available power from the TEG is obtained when Eq. (1) is valid, which is true when $R_{i n}=R_{L}$. In other words, the maximum power is delivered to the load when the input voltage of the converter is half of the TEG's open circuit voltage. In that case, the total maximum power of a string of TEMs can be found using Eq. (2) and (3).

$$
\begin{gathered}
d \frac{P_{R_{L}}}{d R_{L}}=\frac{d}{d R_{L}}\left(\frac{V^{2} R_{L}}{\left(R_{\text {in }}+R_{L}\right)^{2}}\right)=0 \\
P_{R L \text { max-series }}=\frac{1}{4} \Sigma \frac{\left(V_{n}\right)^{2}}{R_{n}} \\
P_{\text {RLmax-parallel }}=\frac{1}{4} \Sigma \frac{\left(\frac{V_{n}}{R_{n}}\right)^{2}}{\frac{1}{R_{n}}}
\end{gathered}
$$

where $P_{R_{L}}$ is the delivered power to the load, $V$ is the equivalent open circuit voltage, $R_{i n}$ is the total internal resistance of the TEG and $R_{L}$ is the load. $V_{n}$ and $R_{n}$ in Eq. (2) and (3) are the open circuit voltages of the individual TEMs and the internal resistances, respectively. However, when a converter is used to extract the highest available power, the load resistance seen form the TEG is a function of the actual load at the output of the converter and the duty ratio of the switch. Therefore, a Maximum Power Point Tracker (MPPT) usually is employed in such applications.

The open circuit voltage $\left(V_{o c}\right)$ and internal resistance $\left(R_{i n}\right)$ from Table II were used as the input parameters. The 
TABLE II

SIMULATION RESULTS OF THE RECEIVED POWER [W] TO THE LOAD AND EFFICIENCY [\%] VERSUS THE OPEN CIRCUIT VOLTAGE $V_{O C}$ [V] AND THE INTERNAL RESISTANCE $R_{i n}[\Omega]$.

\begin{tabular}{|l|l|l|l|l|l|l|l|l|l|}
\hline Point & 1 & 2 & 3 & 4 & 5 & 6 & 7 & 8 & 9 \\
\hline Voc & 116.2 & 166.4 & 190.3 & 121.5 & 179.2 & 122.3 & 162.9 & 180.1 & 201.1 \\
\hline Rin & 69 & 75 & 77 & 70 & 76 & 70 & 75 & 76 & 77 \\
\hline Power & 47.1 & 88.7 & 117.6 & 50.7 & 101.3 & 51.4 & 85 & 102.3 & 124 \\
\hline$\eta \%$ & 96.3 & 96.1 & 96.1 & 96.3 & 96 & 96.3 & 96.2 & 96 & 95.6 \\
\hline
\end{tabular}

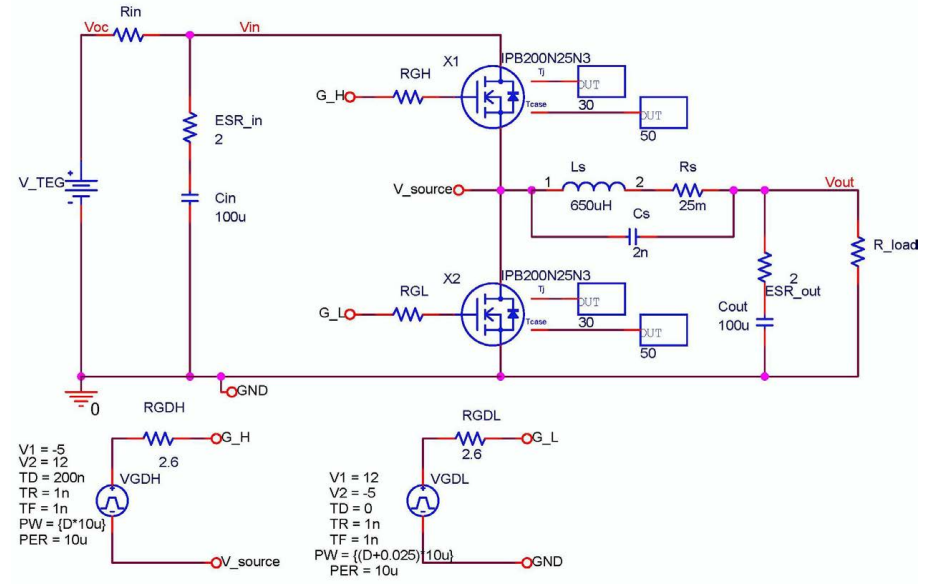

Fig. 4. Schematic diagram of the proposed converter in OrCAD.

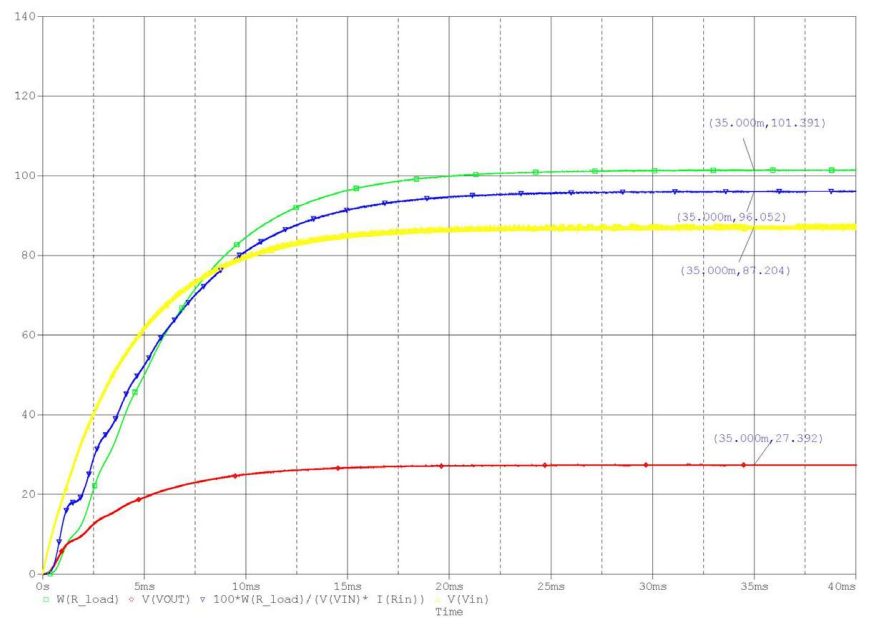

Fig. 5. The simulation result for operating point 8 . The graph shows the output power, efficiency, input and output voltage of the converter. The output power reaches $101 \mathrm{~W}$ at $35 \mathrm{~ms}$ and the efficiency is $96 \%$ at that point.

simulation was run to $40 \mathrm{~ms}$ and as seen in Fig. 5 the power reaches the steady state at approximately $30 \mathrm{~ms}$. The simulation results of all operating points are collected and can be seen in Table II. The converter efficiency stays over $95.6 \%$ for all engine operating points. Using Eq. (4) the total losses in the switch can be calculated. According to the calculation based on Eq. (4) the switches consume approximately $1 \mathrm{~W}$, and that is the case for the inductor and the capacitors as well. The theoretical value for losses in the system is approximately
TABLE III

INDUCTOR PARAMETERS.

\begin{tabular}{|l|l|}
\hline Core & ETD58 \\
\hline Wire type & $\begin{array}{l}\text { Litz CLI } \\
200 / 60\end{array}$ \\
\hline Num. of wires & 6 \\
\hline Num. of turns & 45 \\
\hline Inductance & $650 \mu H$ \\
\hline Resistance & $25 m \Omega$ \\
\hline Capacitance & $2 n F$ \\
\hline
\end{tabular}

$4 \mathrm{~W}$ for the points with highest power which is confirmed by the simulations results as well.

$$
P_{t o t_{s w}}=P_{s w}+P_{\text {cond }}=F_{s}\left(E_{O N}+E_{O F F}\right)+R_{O N} I^{2} D
$$

\section{EXPERIMENTAL RESULTS}

A printed circuit board with the proposed components was designed and built. The gate signal to the switches was generated by a low-cost microprocessor where a perturb and observe MPPT algorithm was also developed and run. The MPPT controlled the extracted power while the output voltage was controlled to keep close to $28 \mathrm{~V}$. The gate driver was supplied by an isolated voltage source with -5 to $+12 \mathrm{~V}$ and therefore the gate signal was varying between those values. Furthermore, calculations on inductor properties were done and an inductor was built according to Table III.

The experimental set up, the power-meter, and the PWM signal can be seen Fig. (7). Due to the expected high efficiency, small heat sinks were used on the switches. To measure the converter performance, a power measurement system with high accuracy was employed and connected to the system. The converter input and output currents and voltages were sampled 10 times when the values became stable. Later on, a mean value of all measurements was calculated from the sampled values and plotted in Fig. (6). The converter showed high performance since the efficiency for all operating points are close to the simulation results and higher than $94.5 \%$ except for point 9 with the highest power. As seen in Fig. (6) the efficiency and the power are related to each other and when the power increases, the efficiency decreases indicating that the losses in the system increase.

\section{CONCLUSION}

In this paper it has been shown that the proposed step-down converter is suitable for a thermoelectric generator and can obtain an efficiency of over $95 \%$. The parameters applied to the converter were from a thermoelectric generator on-board a Scania heavy duty vehicle. The converter was a synchronous one with relatively low-cost silicon MOSFETS as switches, controlled by a maximum power point tracker algorithm to extract highest available power. Due to a nearly complete model, the simulation showed close results to the experimental results. The simulation model can therefore be used to re-design the module connection of the TEG or adjust other parameters if needed. However, it should be noted that the values of power in the simulation and experimental results may differ from each other due to the fact that the input parameters, from the TEG to the converter, are difficult to control and keep 

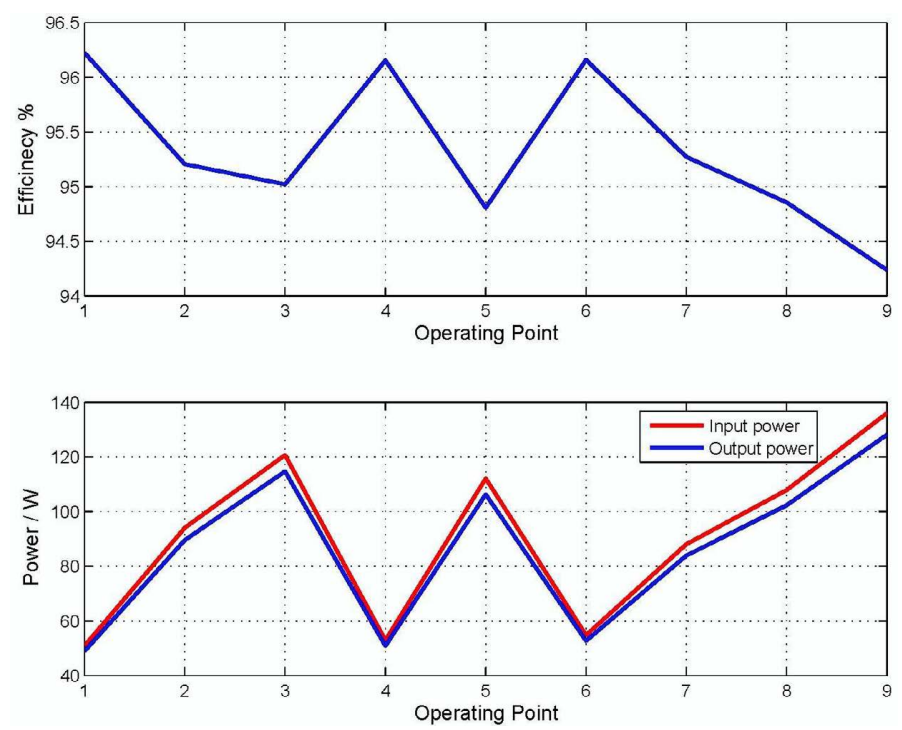

Fig. 6. The experimental result for the step-down converter based on the 9-point engine load. The upper graph shows the efficiency versus operating point and the lower graph show the input and output power.

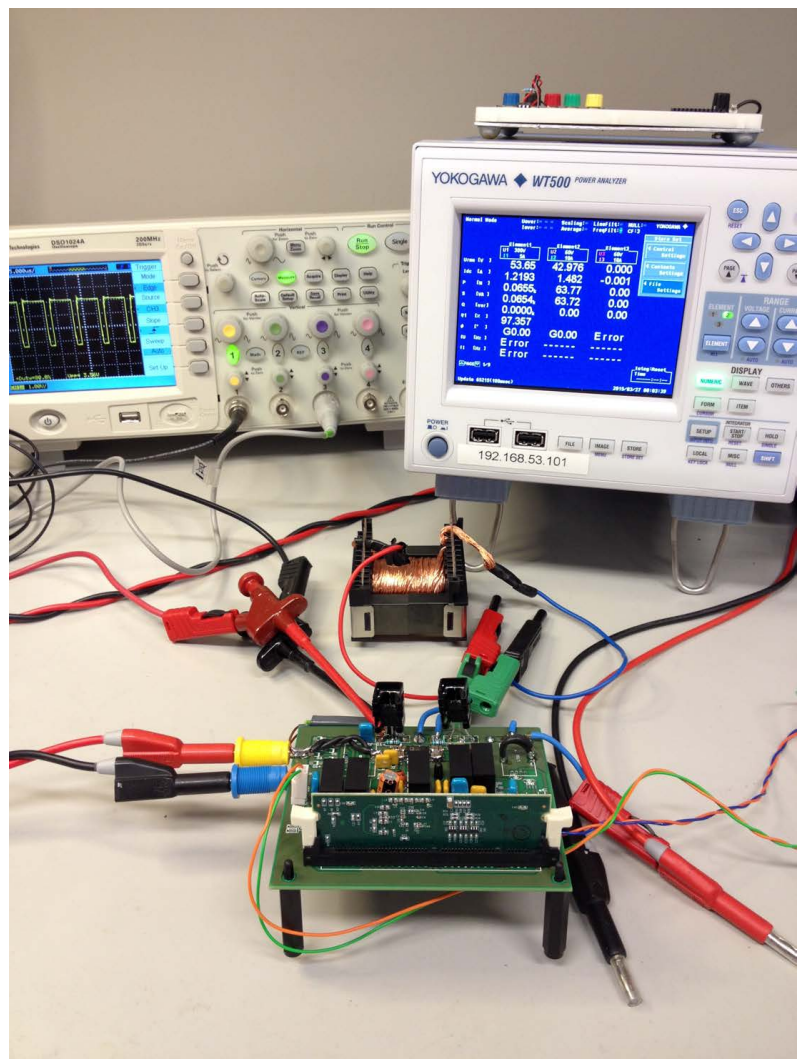

Fig. 7. The experimental setup for the step-down converter.

constant. The converter itself has a few components keeping the cost and losses low. Since the step-down converter has a linear transfer function, the control system does not have to be complicated and therefore a low-cost microprocessor can be used.

In this design, the input and output capacitors and also the inductor values were chosen to have a large margin. If the

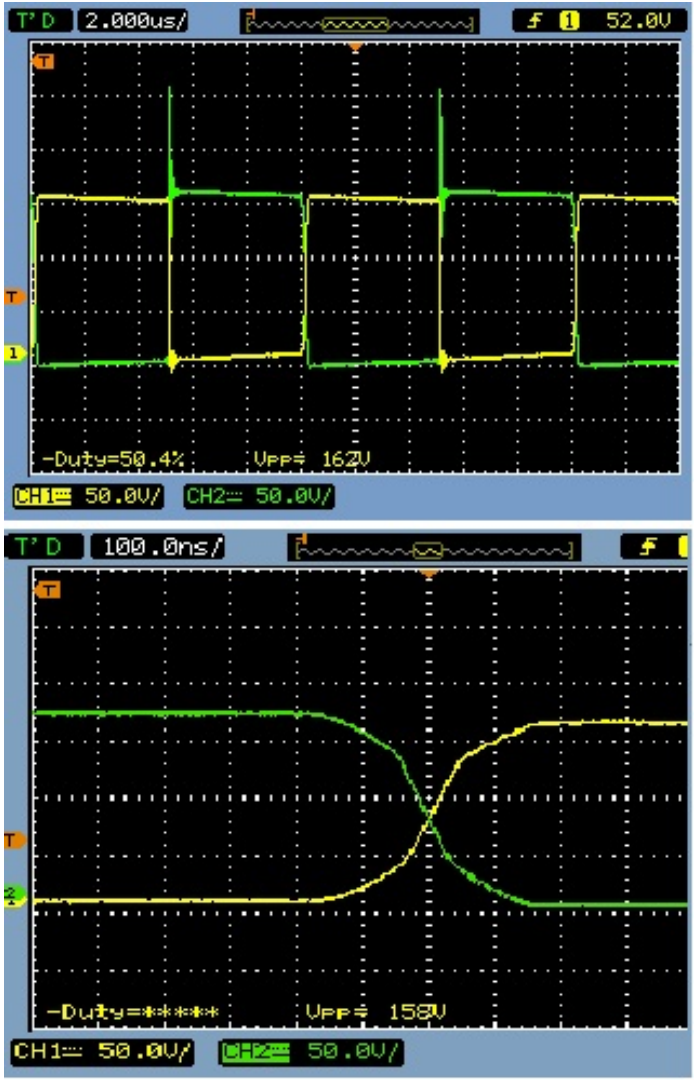

Fig. 8. Measured drain-source voltage over the high-side and low-side switches.

components have lower value but with higher performance, the overall efficiency will be improved additionally. For example, if the inductor is made with a lower inductance value, by means of fewer number of turns, and operates close to discontinuous conduction mode, the losses due to the wire resistance and capacitance will be reduced. However, it should be noted that, in that case, the core losses will increase for the points with lower power. In order to improve the efficiency even more, the switching time can be reduced. This is obtained by employing a lower gate-resistance than used in this work. In Fig. (8) the drain-source voltages of high- and low-side switches are shown. The rise and fall time were measured to 100-200 ns. By decreasing this time, the switching losses can be decreased, improving the efficiency. Furthermore, the level of the gate signal can be increased to $20 \mathrm{~V}$ to decreases the conducting loss in the switches.

\section{REFERENCES}

[1] K. He, H. Huo, Q. Zhang, D. He, F. An, M. Wang, and M. P. Walsh, "Oil consumption and $\mathrm{CO} 2$ emissions in china's road transport: current status, future trends, and policy implications," Energy Policy, vol. 33, no. 12, pp. 1499-1507, Aug. 2005.

[2] X. Yan and R. J. Crookes, "Energy demand and emissions from road transportation vehicles in china," Progress in Energy and Combustion Science, vol. 36, no. 6, pp. 651-676, Dec. 2010.

[3] D. M. ROWE, Ed., "Thermoelectrics Handbook, Macro to Nano", 1st ed. CRC Press Inc, 200512, ch. General Principes and Basic Considerations. 
[4] D. ROWE, Ed., "Thermoelectrics Handbook, Macro to Nano", 1st ed. CRC Press Inc, 200512, ch. A Thermoelectric Application to Vehicles.

[5] I. Laird and D.-C. Lu, "High step-up DC/DC topology and MPPT algorithm for use with a thermoelectric generator," IEEE Trans. Power Electron., vol. 28, no. 7, pp. 3147-3157, Jul. 2013.

[6] L.-x. Ni, K. Sun, H.-f. Wu, Z. Chen, and Y. Xing, "A high efficiency step-up DC-DC converter for thermoelectric generator with wide input voltage range," in 2012 IEEE International Symposium on Industrial Electronics (ISIE), May 2012, pp. 52-57.

[7] J. Kim and C. Kim, "A dc-dc boost converter with variation-tolerant mppt technique and efficient zcs circuit for thermoelectric energy harvesting applications," IEEE Trans. Power Electron., vol. 28, no. 8, pp. 3827-3833, Aug. 2013.

[8] S. Carreon-Bautista, A. Eladawy, A. N. Mohieldin, and E. Snchez-Sinencio, "Boost converter with dynamic input impedance matching for energy harvesting with multi-array thermoelectric generators," IEEE Trans. Ind. Electron., vol. 61, no. 10, pp. 5345-5353, Oct. 2014.

[9] J. W. Kimball, T. L. Flowers, and P. L. Chapman, "Low-input-voltage, low-power boost converter design issues," IEEE Power Electron. Lett., vol. 2, no. 3, pp. 96-99, Sep. 2004.

[10] A. E. Risseh and H. P. Nee, "Design of high-efficient converter for on-board thermoelectric generator," in 2014 IEEE Conference and Expo Transportation Electrification Asia-Pacific (ITEC), Aug. 2014, pp. 1-6. 